\title{
Conhecimento de mulheres em idade fértil sobre o papiloma vírus humano
}

Recebido em: 18/06/2011

Aceito em: 26/07/2011
Kássia Costa Pereira ${ }^{1}$

Thais Benvindo Assunção ${ }^{1}$

Laiana Kátia Silvina de Sousa ${ }^{1}$

Milena France Alves Cavalcante ${ }^{2}$

O Papiloma Vírus Humano (HPV) é um agente de transmissão sexual que se manifesta através de lesões conhecidas como condiloma acuminado e que predispõe ao câncer de colo uterino. O estudo tem por objetivo analisar o conhecimento de mulheres em idade fértil sobre o HPV. Utilizouse a abordagem qualitativa e por meio de entrevista semiestruturada. O cenário da investigação foi um hospital de referência em oncologia em Teresina, Piauí, Nordeste do Brasil. A análise resultou em três categorias, sendo uma delas iluminada pelo referencial de Orem, o HPV e o autocuidado: sentimentos inerentes à descoberta da doença. Nos resultados, evidenciou-se a fragilidade do conhecimento dos sujeitos sobre a doença, ressaltando-se a importância da realização do exame como principal forma de autocuidado.

Descritores: Infecções por Papiloma Vírus, Saúde da Mulher, Enfermagem.

\section{Women at childbearing age awareness about the human papiloma virus}

The Human Papilloma Virus (HPV) is a sexually transmitted agent that manifests itself in lesions known as condyloma acuminata and predisposes to cancer of the cervix. The objective of this study is the knowledge of women at childbearing age on HPV. We used a qualitative approach and by means of semi-structured interview. The scenary of this investigation was an oncology referral hospital in Teresina/Piaui/Northeast of Brazil. The analysis resulted in three categories, one of which is illuminated by reference Orem, HPV and self-care, feelings related to the discovery of the disease. The results showed the fragility of the subjects' knowledge about the disease. However, it was stressed the importance of the examination as the primary form of self-care.

Descriptors: Papillomavirus Infeccions, Women's Health, Nursing.

\section{El conocimiento de las mujeres en edad fértil sobre el virus del papiloma humano}

El Virus del Papiloma Humano (HPV) es un agente de transmisión sexual que se manifiesta en lesiones conocidas como condiloma acuminado y predispone al cáncer de cuello del útero. El objetivo de este estudio, el conocimiento de las mujeres en edad fértil sobre el HPV. Se utilizó un enfoque cualitativo y por medio de entrevista semi-estructurada. La configuración de esta investigación fue un hospital de referencia de oncología en Teresina-PI. El análisis resultó en tres categorías, una de ellas está iluminada por referencia Orem, el HPV y el cuidado personal, los sentimientos relacionados con el descubrimiento de la enfermedad. Los resultados mostraron la fragilidad de los temas del conocimiento sobre la enfermedad. Sin embargo, se destacó la importancia del examen como la principal forma de auto-cuidado.

Descriptores: Infecciones por Papilomavirus, Salud de la Mujer, Enfermería.

\section{INTRODUÇÃO}

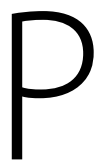
apiloma Vírus Humano (HPV) é uma doença infecciosa de transmissão sexual, que tem elevada prevalência em ambos os sexos, ocorrendo assim de modo universal, embora outras formas tenham sido identificadas. É também conhecida como condiloma acuminado, verruga genital, crista de galo, figueira, cavalo de crista ou jacaré de crista, podendo ocasionar lesões que, se não tratadas, podem se transformar em câncer de colo de útero ${ }^{(1-2)}$.

Dessa forma, principal precursor do câncer de colo de útero, o HPV é um DNA-vírus da família Papoviridae, gênero papiloma vírus, com uma variabilidade de subtipos, englobando mais de 100 tipos reconhecidos atualmente, definidos pela análise da sequência de DNA, 20 dos quais podem infectar o trato genital. O papiloma vírus humano está associado a um espectro amplo de doenças, que variam desde a verruga vulgar até o carcinoma invasivo do trato genital ${ }^{(1-2)}$.

Ao contrário do que se pode pensar, atualmente, cerca de $5 \%$ a $15 \%$ das mulheres previamente sem o vírus HPV são infectadas com qualquer tipo de HPV de alto risco e aproximadamente $25 \%$ da incidência da infecção se concentra na faixa etária dos 15 a 19 anos. No Brasil, a incidência registrada foi de $8,1 / 100$ pessoas por ano. Outro estudo com a população brasileira registrou uma incidência de $14,3 \%$ de infecção genital por HPV de alto risco, sendo $77,8 \%$ das lesões escamosas de alto grau e $100 \%$ 
dos casos de carcinoma. Estima-se que cerca de 105 milhões de mulheres no mundo inteiro terão infecção pelo HPV 16 ou 18 pelo menos uma vez na vida, sabendo, assim, que o número de mulheres portadoras do DNA do vírus HPV em todo mundo chega a 291 milhões $^{(3)}$.

Por esse prisma, o Brasil é um dos líderes mundiais em incidência de HPV, com acometimento notório em mulheres entre 15 e 25 anos, embora a doença também esteja presente entre os homens. Dados do Ministério da Saúde registram cerca de 137 mil novos casos anualmente, estando o HPV associado a $90 \%$ dos casos de câncer de colo de útero no Brasil. Consoante o Instituto Nacional do Câncer (Inca), a doença poderá se desenvolver ou não, dependendo não só do tipo de HPV, mas de outros fatores relacionados com o hospedeiro, o estado imunológico, o tabagismo e o uso de contraceptivo oral ${ }^{(4)}$.

$O$ estudo tem por objetivo analisar o conhecimento de mulheres em idade fértil sobre o papiloma vírus humano.

\section{MÉTODOS}

Pesquisa qualitativa, exploratório-descritiva, que permite a exploração de uma situação em que se tem a necessidade de maiores informações, possibilitando a utilização de seus resultados para a orientação e o melhoramento de práticas. Utilizamos a abordagem qualitativa por entendermos que o estudo necessita de dados subjetivos, relacionados ao contexto social dos sujeitos que vivenciam a realidade proposta, ou seja, os aspectos inerentes ao conhecimento das mulheres em relação ao HPV e a seus fatores de risco.

A pesquisa foi realizada em maio de

"Só sei que é doença [o papiloma vírus] sexualmente transmissível; tem que se cuidar, né, pra não pegar, né. Agora, não sei muito não. Mas se não se prevenir..."
"(...) eu tive isso aí, falei para meu marido, é (...). Fiquei assim deprimida. Aí disse pra ele. Aí ele disse que não tinha saído com ninguém e que o problema não era com ele, e eu peguei de quem? (...) fiquei com muito medo, abalada, e chorava muito mesmo (...) pensei fui procurar nele, eu procurei na virilha, ele negava sempre que não tinha me traído." (Dep. 14)

O medo é a emoção negativa mais comum; mais do que isso: é um dos mais fortes delineadores da personalidade das pessoas, influenciando o que pensamos poder ou não fazer. A reação do parceiro é motivo para preocupação ainda, visto que, ao conhecer que o HPV é uma doença de transmissão sexual, a questão da fidelidade aflora, tornando-se imprescindível o diálogo e o questionamento da conduta sexual ${ }^{(5-7)}$.

Quando informadas de que alguns tipos de HPV têm implicações na gênese do câncer de colo uterino, o medo é um sentimento dominante, revelando o fantasma do câncer como uma força destruidora, uma doença invasiva e silenciosa. O medo do prejulgamento dos indivíduos e da descoberta da família gera no portador dificuldades de compartilhar o sofrimento com familiares, cônjuges e amigos ${ }^{(8-10)}$.

"Não fazer o exame de prevenção (...) Tem que ir se cuidando enquanto é cedo." (Dep. 3)

"Doença sexualmente transmissível, só sei isso, queédoença sexualmente transmissível; tem que se cuidar, né, pra não pegar. Agora, não sei muito, não. Mas se não se prevenir..." (Dep. 13)

O HPV compromete o funcionamento do organismo, causando danos à saúde, sendo necessário que essas mulheres sejam agentes ativos do autocuidado, procurando adesão ao tratamento, assiduidade nas consultas e realização de cuidados prescritos. Os níveis socioeconômico e educacional baixos, a instabilidade emocional, a negação, os sentimentos de culpa, os problemas familiares, sobretudo os conjugais, tendo em vista que a patologia envolve questões de infidelidade e a baixa adesão do uso do condom pelos parceiros, são fatores geralmente encontrados nesse grupo, que, por vezes, interferem na realização de medidas de autocuidado $^{(11)}$.

"Não ter uma boa higiene e ter vários parceiros. Parece que se pega na relação sexual." (Dep. 8)

Quanto às medidas de apoio e tratamento do HPV, recomenda-se a associação de vitaminas para aumentar a resistência (vitamina $A$, complexo $B$ e $C$ ), bem como medidas higiênicas, abstinência sexual, utilização de preservativos e do espermicida, que podem reduzir o risco de contaminação por HPV. Portanto, o uso do preservativo em todas as relações sexuais, mesmo que se tenha parceiro único, vem se mostrando a forma mais viável de prevenção e de autocuidado ${ }^{(12)}$.

"Fiquei muito triste, sei lá, meio esquisita, sem saber como seria de agora para a frente, com este vírus." (Dep. 10)

A carência de informações adequadas sobre o HPV favorece o desenvolvimento de concepções errôneas, que podem 
interferir no comportamento da portadora do HPV e das pessoas que fazem parte de seu contexto sociofamiliar. Na maioria das vezes, essas concepções errôneas encontram-se carregadas de elementos culturais, tais como crenças, mitos e tabus, que possuem significado para o indivíduo. Os valores culturais sem correspondência com a realidade podem representar barreiras para os profissionais que atuam na promoção da saúde e na prevenção de doenças ${ }^{(13)}$.

Portanto, é a mulher que se encontra em maior grau de vulnerabilidade, não apenas biológica, mas também em razão de fatores socioeconômicos e de gênero. A tristeza é manifestada pela possibilidade de recidiva, já que, ao descobrir ser portadora do HPV, ela pode vir a experimentar o desenvolvimento de diversos sentimentos, principalmente por tratar-se de uma DST relativamente desconhecida e que pode levar à morte através do câncer de colo de útero. Seu diagnóstico pode, também, gerar mudanças de comportamento na mulher,

"É a mulher que se

encontra em maior grau

de vulnerabilidade, não apenas biológica, mas

\section{também em razão de}

fatores socioeconômicos

$$
\text { e de gênero" }
$$

sobre os sinais, a prevenção e o tratamento. Ressalta-se a essas mulheres com os aspectos inerentes ao autocuidado.

Nessa perspectiva, o enfermeiro deve reconhecer até que enfermeiro deve ainda estar voltada para uma atenção para essas mulheres.

O HPV, em decorrência de sua divulgação pelos diversos órgãos de comunicação, integra-se aos problemas de saúde pública e, mesmo com toda a divulgação, ainda é uma doença desconhecida, tornando-se motivo de preocupação para os gestores e os profissionais da saúde e para a população. Por isso, torna-se imprescindível o desenvolvimento de ações educativas que causam impactos nos clientes e profissionais de saúde, através de investimentos nas gestões e ações de saúde mais diretas para o controle do HPV. Por fim, é por meio de um trabalho conjunto e integrado com os serviços de saúde e com os profissionais que a população terá subsídios para obter melhor qualidade de vida.

$O$ estudo possibilitou identificar o baixo conhecimento mulheres sobre a doença HPV e a falta de informação adequada

\section{Referências}

1. Cimerman S, Cimerman B. Condutas em infectologia. São Paulo: Atheneu; 2004.

2. Nakagawa T, Schirmer J, Barbieri, M. Vírus HPV e câncer de colo de útero. Rev Bras Enferm. 2010;36(3):253-7.

3. Arlindina N. O HPV e as respectivas ações de enfermagem. 2010;10(4):210-7. 4. Smeltzer C, Bare G. Tratado de enfermagem médico-cirúrgica. Rio de Janeiro: Guanabara Koogan; 2008.

5. Sousa B, Pinheiro B, Barroso T. Ser mulher portadora do HPV: uma abordagem cultural. Rev Esc Enferm USP. 2008;42(4):56-0.

6. Forones M, Jesus R, Tadocoro H. Oncologia. São Paulo: Manole; 2005. 7. Santos C. A enfermagem na assistência à saúde e prevenção do HPV no homem. Rev Pesqui Cuid Fundam. 2009.

8. Amorim V. Fatores associados à não-realização do exame Papanicolau: um estudo de base populacional no município de Campinas. Cad Saúde Pública. 2006;22(11):43-50.

9. Ministério da Saúde (BR). Controle dos cânceres do colo do útero e da mama. Brasilia: Ministério da Saúde; 2006.

10. Caldas I, Teixeira M, Rafael R. O Papilomavírus Humano como fator

preditor do câncer do colo uterino: estudo de atualização sobre as ações preventivas de enfermagem. Rev Enferm. 2010;10(15):65-70.

11. Ministério da Saúde (BR). Secretaria de Vigilância em Saúde.

Departamento de Vigilância Epidemiológica. Doenças infecciosas e

parasitárias: guia de bolso. Brasilia: Ministério da Saúde; 2010.

12. Nadal R, Manzione R. Vacina contra o Papilomavírus Humano. O que é preciso saber? Rev Bras Colo-Proctol. 2010;30(2):237-40.

13. Ministério da Saúde (BR). Secretaria de Políticas de Saúde Departamento de Atenção Básica Área Técnica de Dermatologia Sanitária. Brasilia: Ministério da Saúde; 2006.

14. Queiroz T, Pessoa F, Sousa A. Infecção pelo Papiloma vírus humano (HPV): incertezas e desafios. Acta Paul Enferm. 2005;18(4):110-8.

15. Diógenes M, Carvalho A, Silva H. Desvios de saúde em portadoras de condiloma vulvar. Rev RENE. 2009;18(10):56-66. 